\title{
SUSCEPTIBILITY OF NEWBORN RATS TO HEPATOTOXICITY OF 1,3-DIBROMOPROPANE AND 1,1,2,2-TETRABROMOETHANE, COMPARED WITH YOUNG RATS
}

\author{
Mutsuko HIRATA-KOIZUMI ${ }^{1}$, Osamu KUSUOKA ${ }^{2}$, Nobuo NISHIMURA ${ }^{2}$, Hajime WADA $^{3}$, \\ Hidehiro OGATA ${ }^{3}$, Naemi FUKUDA ${ }^{4}$, Yoshihiko ITO $^{4}$, Eiichi KAMATA ${ }^{1}$, \\ Makoto EMA ${ }^{1}$ and Ryuichi HASEGAWA ${ }^{1}$ \\ ${ }^{1}$ National Institute of Health Sciences, 1-18-1 Kamiyoga, Setagaya-ku, Tokyo 158-8501, Japan \\ ${ }^{2}$ Gotemba Laboratory, Bozo Research Center Inc., 1284 Kamado, Gotemba-shi, Shizuoka 412-0039, Japan \\ ${ }^{3}$ Panapharm Laboratories Co., Ltd., 1285 Kurisakimachi, Uto-shi, Kumamoto 869-0425, Japan \\ ${ }^{4}$ Research Institute for Animal Science in Biochemistry and Toxicology, \\ 3-7-11 Hashimotodai, Sagamihara-shi, Kanagawa 229-1132, Japan
}

(Received July 22, 2004; Accepted December 10, 2004)

\begin{abstract}
Newborn rat studies were conducted with oral administration of 1,3-dibromopropane (DBP) and 1,1,2,2-tetrabromoethane (TBE) from postnatal Days 4 to 21 to allow comparison of NOAELs and unequivocally toxic levels with those from 28-day young rat studies starting at 5-6 weeks of age. The unequivocally toxic level was estimated by our specified criteria, requiring simultaneous change of organ weights, histopathology, some biochemical parameters and body weights, because in this study only hypertrophy of hepatocytes was observed as a major histopathological change. DBP caused centrilobular hypertrophy of hepatocytes with alteration in biochemical parameters, as well as lowering of body weights, regardless of sex, in both newborn and young rats. NOAELs and unequivocally toxic levels were considered to be 50 and $150 \mathrm{mg} / \mathrm{kg} / \mathrm{day}$ in newborn rats and 10 and $250 \mathrm{mg} / \mathrm{kg} / \mathrm{day}$ in young rats, respectively. In the newborn rat study of TBE, some hepatic effects observed at the top dose of $50 \mathrm{mg} / \mathrm{kg}$ were not considered adverse because of the lack of histopathological changes. Significant lowering of body weight was noted at $200 \mathrm{mg} / \mathrm{kg}$ in the dose-finding study but histopathological data were not available. In the young rat study, there was no definite toxicity at $6 \mathrm{mg} / \mathrm{kg}$ and hypertrophic changes in liver and thyroids without body weight change occurred at $200 \mathrm{mg} / \mathrm{kg}$. There were no clear sex differences in both the newborn and young rat studies. NOAELs were considered to be 50 and $6 \mathrm{mg} / \mathrm{kg} / \mathrm{day}$ in newborn and young rats, respectively, but unequivocally toxic levels for both rats could not be estimated. Abnormalities of external and sexual development and reflex ontogeny in the newborn were not observed with either chemical. Based on these results, it can be concluded that the target organ of DBP and TBE is the liver in both newborn and young rats, and that while the doses at which toxic signs began to appear are higher in newborn rats, those causing clear toxicity may be paradoxically lower in the newborn case.
\end{abstract}

KEY WORDS: Toxicity in newborn rats, 1,3-Dibromopropane, 1,1,2,2-Tetrabromoethane

\section{INTRODUCTION}

The newborn period is a time of biological changes because birth creates a completely new situation for the offspring. For example, prior to birth, maternal and fetal blood are in close equilibration, and most xenobiotics that cross the placenta to the fetus must shift back to the mother again because the ability of the fetus to dispose of them is extremely immature (Scheuplein et al., 2002). After elimination of compounds across the placenta ceases at birth, metabolic and excretory functions rapidly develop. In the liver, parturition triggers the dramatic development of metabolic enzymes (Alcorn and McNamara, 2002). In man, 


\section{HIRATA-KOIZUMI et al.}

most enzymes have matured to adult activity levels by the first year of life, but cytochrome P450-mediated metabolism, glucuronidation, glutathione conjugation and acetylation are generally deficient in the neonate. Regarding renal clearance, although the adult function is also approached by 1 year of age, the faster development of filtering than absorptive or secretory functions results in a glomerulotubular imbalance. The lack of a balanced detoxication ability during the newborn period would be expected to affect toxicity of chemicals.

For the toxicity evaluation of various kinds of chemicals, repeated dose and reproductive/developmental toxicity studies have been generally conducted. However, the effects of direct exposure to chemicals during the newborn period have not been taken into account. Furthermore, there were no sufficient data on the differences between the newborn and young/adult in the susceptibility to the toxicity of chemicals. Therefore, for the purpose of understanding the sensitivity of the newborn and utilizing it in the toxicity evaluation, we conducted the repeated dose toxicity studies using newborn rats, and analyzed the differences of the sensitivity from that of young rats, which have been recently used to evaluate the chemical toxicity in general. These comparative studies were conducted as a part of an existing chemical testing program of Japan. As the candidate chemicals, phenolic and halogenated compounds were selected among chemicals in this program, considering the potential for endocrine disrupting action in the early development period. Because of no standard experimental protocol, repeated dose toxicity studies in newborn rats were conducted with our newly established protocol (Koizumi et al., 2001), including a detailed examination of early development and a complete toxicity analysis after a sufficient recovery-maintenance period. The results were compared with those of a 28-day repeated dose toxicity study using young rats, which is generally conducted as a screening test in existing chemical testing program in Japan. For more precise comparison, in addition to the no observed adverse effect levels (NOAELs), we estimated unequivocally toxic levels, defined as doses inducing clear toxicity, including clinical toxic signs, death or critical histopathological damage. In order to estimate more appropriate NOAELs and unequivocally toxic levels than those depending on the dosages of main studies, the results of dose-finding studies for each case were incorporated. Earlier, we reported analytical results for five chemicals (4-nitrophenol, 2,4dinitrophenol, 3-aminophenol, 3-methylphenol, tetra- bromobisphenol A) (Koizumi et al., 2001, 2002, 2003; Fukuda et al., 2004). The susceptibility of newborn rats to the toxicity of the first four was 2 to 4 times higher than that of their young counterparts, although these chemicals had no impact on development in the newborn period and showed similar toxicity profiles in both age groups (mainly effects on the central nervous system). In the case of tetrabromobisphenol A, a specific rather than enhanced renal toxicity was observed in newborn rats.

In the present study, two halogenated alkanes, 1,3-dibromopropane (DBP) and 1,1,2,2-tetrabromoethane (TBE), were chosen as the sixth and seventh chemicals for comparative toxicity analysis, because these two chemicals have similar properties such as analogous chemical structures and hepatotoxicity after hepatic metabolism, and the lower susceptibility of the newborn to these chemicals was expected in preliminary analysis, contrary to all outcomes of previous analyses. There has hitherto been no sufficient information on toxicity of DBP, an intermediate in the production of pharmaceutical agents (Chemical Products' Handbook, 2004), except that the intraperitoneal lowest lethal dose is $750 \mathrm{mg} / \mathrm{kg}$ in mice (Sax, 1979). Applications of TBE are various as a fire retardant, in oils and fats, in solvents, for ore dressing, and as a reagent for microscopic examination and as a catalyst (Chemical Products' Handbook, 2004). Regarding its toxicity, inhalation exposure to TBE for 180-184 days ( 7 hr/day, 5 days/week) caused slight edema and congestion in lungs and slight centrilobular fatty degeneration in the livers of mice, rats, guinea pigs and rabbits at an average concentration of $4 \mathrm{ppm}$ (Hollingsworth et al., 1963). Gavage studies for 3 weeks using F344/N male rats have been conducted on many halogenated ethanes to examine renal toxicity, but all rats administered TBE (214 mg/kg/day and more) died or were killed on becoming moribund by dosing Day 11 (NTP, 1996). Cytoplasmic vacuolization of hepatocytes was observed in these rats. We have conducted the newborn rat studies on DBP and TBE and evaluated the results in comparison with published findings in young rats (MHLW, 2003a, 2003b), in the same manner as for the five chemicals already documented (Koizumi et al., 2001, 2002, 2003).

\section{MATERIALS AND METHODS}

\section{Materials}

1,3-Dibromopropane (DBP, CAS No. 109-64-8, purity: $99.8 \%$ ) and 1,1,2,2-tetrabromoethane (TBE, 
Susceptibility of newborn rats to 1,3-dibromopropane and 1,1,2,2-tetrabromoethane.

CAS No. 79-27-6, purity: 99.2\%) were obtained from TOSOH CORPORATION (Tokyo, Japan), and dissolved in corn oil and olive oil, respectively. Test solutions were prepared at least once a week and kept cool and in the dark until dosing. The stability was confirmed to be at least 7 days under these conditions. All other reagents used in this study were specific purity grade.

\section{Animals}

Sprague-Dawley SPF rats [Crj:CD(SD)IGS] were purchased from Charles River Japan Inc. (Kanagawa, Japan) and maintained in an environmentally controlled room at $19-27^{\circ} \mathrm{C}$ with a relative humidity of $32-75 \%$, a ventilation rate of more than 10 times per hour, and a 12:12 hr light/dark cycle. For 18-day newborn rat studies of DBP and TBE, 20 pregnant rats (gestation Day 14) were purchased for each and allowed to deliver spontaneously. All newborn were separated from dams at postnatal Day 3 (the date of birth was defined as postnatal Day 0), and those with good health without external abnormality were pooled according to sex. Groups of 12 males and 12 females were selected and assigned to each of the 4 dose groups, including the controls, by stratified random sampling based on the body weight. Twelve foster mothers were selected based on health and nursing conditions, and suckled the 4 males and 4 females assigned to each group up to weaning on postnatal Day 21 (termination of dosing). After weaning, the animals of the recovery-maintenance group (see Study design) were individually maintained for 9 weeks. In the 28day study of young rats, 4 week-old rats were obtained and used at ages of 5-6 weeks after acclimation. All animals were allowed free access to basal diet (CRF-1: Oriental Yeast Co. Ltd., Tokyo, Japan, or LABO MR Stock: Nihon Nosan Kogyo Inc., Yokohama, Japan) and water (tap water or well water treated with sodium hypochlorite).

\section{Study design (Time schedule as reported previously (Koizumi et al., 2001))}

\section{18-Day repeated dose study in newborn rats}

In a dose-finding study, DBP was administered by gastric intubation to newborn rats ( $5 / \mathrm{sex} / \mathrm{dose})$ from postnatal Days 4 to 21 and TBE from postnatal Days 4 to 20 . The dosages were set at $0,10,30,100$ or $200 \mathrm{mg} /$ $\mathrm{kg} /$ day for DBP and at $0,12,50$ or $200 \mathrm{mg} / \mathrm{kg} /$ day for TBE, based on the results of young rat study, mentioned below. They were examined for general behavior and body weights during the dosing period, and sacrificed at postnatal Day 21 or 22 for assessment of hematology, blood biochemistry, macroscopic findings and organ weights.

In the main study, newborn rats (12/sex/dose) were administered test substances by gastric intubation from postnatal Days 4 to 21. Based on results of the dose-finding study, the dosage was set at 10,50 or 150 $\mathrm{mg} / \mathrm{kg} /$ day for DBP and 3,12 or $50 \mathrm{mg} / \mathrm{kg} /$ day for TBE. On postnatal Day 22, 6 males and 6 females in each treated group were sacrificed (the scheduled-sacrifice group) and the rest of animals in all groups (6/ sex/dose) were maintained for 9 weeks without chemical treatment and then sacrificed at 12 weeks of age (the recovery-maintenance group). During the study, general behavior, body weight and food consumption (only the recovery-maintenance period) were examined at least once a day. In addition, some developmental parameters were assessed, such as surface righting and visual placing reflex for reflex ontogeny, fur appearance, incisor eruption and eye opening for external development, and preputial separation, vaginal opening and estrous cycle for sexual development. Urinalysis (color, $\mathrm{pH}$, occult blood, protein, glucose, ketone bodies, bilirubin, urobilinogen, sediment, volume of the urine, osmotic pressure) was conducted in the late recovery-maintenance period.

At weaning age of postnatal Day 22 after the last treatment, blood was collected under anesthesia from the abdomen of all animals in the scheduled-sacrifice group. In the recovery-maintenance group, it was conducted at 85 days of age after overnight starvation. One portion of the blood was treated with EDTA-2K and examined for hematological parameters such as the red blood cell count (RBC), hemoglobin (Hb), hematocrit (Ht), mean corpuscular volume, mean corpuscular hemoglobin, mean corpuscular hemoglobin concentration, white blood cell count, platelet count, reticulocyte count and differential leukocyte count. In the recoverymaintenance group, blood was also treated with 3.8\% sodium citrate and blood clotting parameters such as prothrombin time and activated thromboplastin time were examined. Serum or plasma from the remaining portions of blood were analyzed for blood biochemistry (total protein, albumin, albumin-globulin (A/G) ratio, glucose, total cholesterol, triglycerides, phospholipid, total bilirubin, urea nitrogen, creatinine, glutamate oxaloacetate transaminase (GOT), glutamate pyruvate transaminase (GPT), alkaline phosphatase, $\gamma$-glutamyl transpeptidase $(\gamma$-GTP), calcium, inorganic phosphorus, sodium, potassium, chlorine). Following collection of blood, all animals were 
sacrificed by exsanguination, and organs and tissues of the entire body were macroscopically observed. The brain, pituitary gland, thymus, thyroids, heart, lungs, liver, spleen, kidneys, adrenals, testes, epididymides, ovaries and uterus were weighed, and fixed in 10\% buffered formalin-phosphate (following Bouin's fixation for testes and epididymides). Paraffin sections were routinely prepared and stained with hematoxylineosin for microscopic examination. All studies were conducted in compliance with the Good Laboratory Practice Act of the Japanese Government.

\section{28-Day repeated dose study in young rats}

In a dose-finding study, DBP and TBE were administered by gastric intubation to five-week old rats ( 5 or $4 / \mathrm{sex} /$ dose) for 14 days. The dosages were determined at $0,20,60,200$ or $600 \mathrm{mg} / \mathrm{kg} /$ day for DBP, and at $0,10,20,50,100$ or $200 \mathrm{mg} / \mathrm{kg} / \mathrm{day}$ for TBE, based on the results of the preliminary single-dose study. The general behavior, body weight and food consumption were examined, and the animals were sacrificed the day after the last treatment for assessment of hematology, blood biochemistry, macroscopic findings and organ weights.

Referring to the results of the dose-finding study, doses in a main study were set at 10,50 and $250 \mathrm{mg} /$ $\mathrm{kg} /$ day for DBP and at 6, 20, 60 and $200 \mathrm{mg} / \mathrm{kg} /$ day for TBP. In the main study, 5-6 week old rats were given the test substances by gastric intubation daily for 28 days and sacrificed after overnight starvation following the last treatment (scheduled-sacrifice group). Recovery groups $(0,50,250 \mathrm{mg} / \mathrm{kg} /$ day for DBP and 0,200 $\mathrm{mg} / \mathrm{kg} /$ day for TBE) were maintained for 2 weeks without chemical treatment and sacrificed at 11 or 12 weeks of age. The number of animals for each sex/dose for both scheduled-sacrifice and recovery cases was 6 for DBP and 5 for TBE. Rats were examined for general behavior, body weight, food consumption, urinalysis, hematology and blood biochemistry, necropsy findings, organ weights and histopathological findings in compliance with the Test Guideline in the Japanese Chemical Control Act (Official Name: Law Concerning the Examination and Regulation of Manufacture, etc. of Chemical Substances) under Good Laboratory Practice conditions.

\section{Statistical analysis}

Parametric data such as body weights, food consumption, urinalysis findings (except for the results of qualitative analysis), hematological and blood biochemical findings, and organ weights were analyzed by Bartlett's test (Bartlett, 1937) for homogeneity of distribution. When homogeneity was recognized, Dunnett's test (Dunnett, 1964) was conducted for comparison between control and individual treatment groups ( $\mathrm{p}<0.01$ or 0.05 ). If not homogenous, the data were analyzed using Steel's multiple comparison test (Steel, 1959) or the mean rank test of the Dunnett type (Hollander and Wolfe, 1973) ( $p<0.01$ or 0.05). If the number of groups was two, parametric data were analyzed by the F test (Snedecor and Cochran, 1967). When homogeneity was recognized, the Student's $t$ test (Steel and Torrie, 1980) was conducted and if not, the Aspinn-Welch's $t$ test (Snedecor and Cochran, 1967) ( $p<0.01$ or 0.05 ). For histopathological findings, the Mann-Whitney's U test (Mann and Whitney, 1947) or the Fisher's exact test (Fisher, 1973) were performed ( $\mathrm{p}<0.01$ or 0.05 ). In the newborn study, the chi square test (Fisher, 1922) was conducted for physical and sexual development and reflex ontogeny $(\mathrm{p}<0.01$ or 0.05 ).

\section{Judgment criteria for NOAEL and the unequivo- cally toxic level}

NOAEL is the greatest dose at which no adverse effects are observed. In the case of hepatotoxicity, increased liver weights or changes in biochemical parameters alone are not considered to be adverse effects. The unequivocally toxic level has been used only for our comparative toxicity analysis as a clear toxic dose. However, it is generally not readily definable because it depends on the type of toxicity. In this study, centrilobular hypertrophy of hepatocytes was observed as a major histopathological change with both chemicals. Appearance of hypertrophic hepatocytes may not be considered to be a sign of clear toxicity because it is not usually accompanied by increase in GOT and GPT, typically found with hepatotoxic agents. Therefore, for the special purposes of this study, the unequivocally toxic level was estimated on the basis of concomitant changes in organ weights, histopathology, biochemical parameters and body weights.

\section{RESULTS}

\section{1,3-Dibromopropane (DBP)}

\section{18-Day study in newborn rats (including the dose- finding study)}

In the dose-finding study at doses of 10, 30, 100 and $200 \mathrm{mg} / \mathrm{kg}, 2$ of 5 males and 2 of 5 females of the highest group died on dosing Days 2 to 3, but no 
Susceptibility of newborn rats to 1,3-dibromopropane and 1,1,2,2-tetrabromoethane.

change in general behavior was observed in the others. In the $200 \mathrm{mg} / \mathrm{kg}$ group, body weights were also lower by $15-25 \%$ than the control values from dosing Day 4 in males and from dosing Day 8 in females. Blood biochemical examination showed a slight increase in total cholesterol in females given $200 \mathrm{mg} / \mathrm{kg}$. For organ weight, increases in relative liver weights were demonstrated in both sexes at $100 \mathrm{mg} / \mathrm{kg}$ and more with absolute liver weights in males at $100 \mathrm{mg} / \mathrm{kg}$. Decrease in absolute and relative testis weights were also observed in males of $200 \mathrm{mg} / \mathrm{kg}$ group. At autopsy, there were no gross abnormalities except hepatomegaly in all animals, including the dead rats at $200 \mathrm{mg} / \mathrm{kg}$. Based on these results, 10,50 and $150 \mathrm{mg} / \mathrm{kg}$ were selected as the doses for the main study in newborn rats.

In the main study, no change in general behavior was noted during the dosing period in any dose group. Body weights of both sexes given $150 \mathrm{mg} / \mathrm{kg}$ were lowered during the dosing period (Fig.1) and gain was also decreased by approx. 10\%. No definitive changes in parameters for external and sexual development and reflex ontogeny were detected in any dose group. At the scheduled sacrifice, blood biochemical examination of the $150 \mathrm{mg} / \mathrm{kg}$ group showed increases in $\gamma$ GTP in males and total bilirubin in females. There were no dose-related changes in hematological parameters. Significant increase of absolute and relative liver weights was noted in males given $50 \mathrm{mg} / \mathrm{kg}$ and in both sexes given $150 \mathrm{mg} / \mathrm{kg}$. The relative liver weights were also increased in females at 10 and $50 \mathrm{mg} / \mathrm{kg}$. Absolute brain weights were lower in both sexes given $150 \mathrm{mg} /$ $\mathrm{kg}$, this being considered due to the lowered body weights. On histopathological examination, hypertrophy of centrilobular hepatocytes was noted in all animals given $150 \mathrm{mg} / \mathrm{kg}$, being mild in $3 / 6$ males and $4 / 6$ females (Table 1). In four of each sex, the endoplasmic reticulum in hypertrophic hepatocytes showed a ground glass appearance. In addition, single cell necrosis was also noted in 3/6 males and 1/6 females at 150 $\mathrm{mg} / \mathrm{kg}$. During and at the end of the recovery-maintenance period, the changes observed in scheduled sacrificed group had disappeared.

The results of the dose-finding study and main study of DBP in newborn rats are summarized in Table 2. The NOAEL was concluded to be $50 \mathrm{mg} / \mathrm{kg} /$ day because increase in liver weight without biochemical and histopathological changes in this dose of the main study was not considered as an adverse effect. The unequivocally toxic level was concluded to be $150 \mathrm{mg} /$ $\mathrm{kg} / \mathrm{day}$, based on increase of liver weight, mild centrilobular hypertrophy of hepatocytes, increase of $\gamma$-GTP and total bilirubin, and lowering of body weights at this dose in the main study, taking additional account of the $40 \%$ mortality rate at $200 \mathrm{mg} / \mathrm{kg}$ in the dose-finding study.
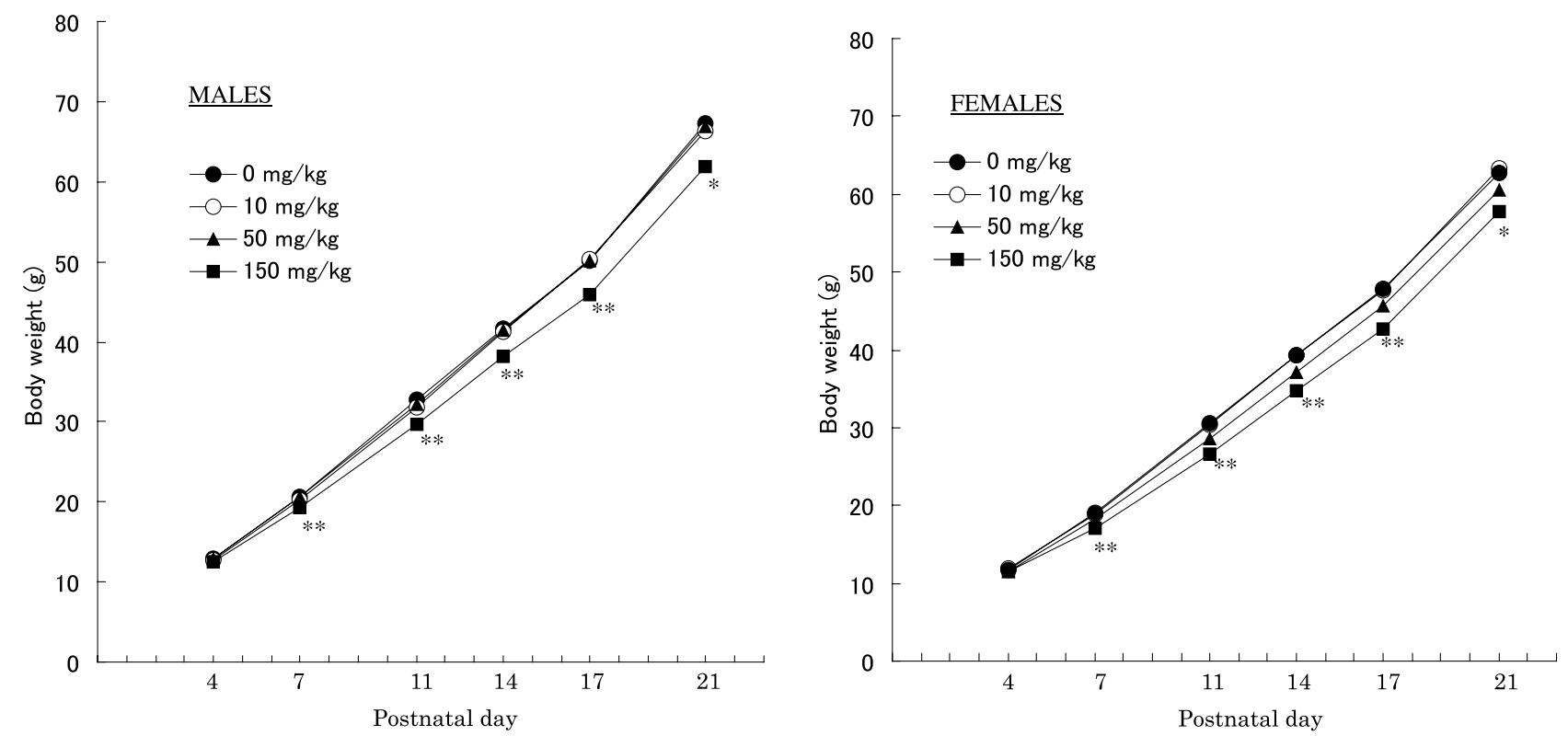

Fig. 1. Body weight curves for the 18-day study of 1,3-dibromopropane in newborn rats.

*: Significantly different from the controls $(\mathrm{p}<0.05)$, **: Significantly different from the controls $(\mathrm{p}<0.01)$. 


\section{HIRATA-KOIZUMI et al.}

\section{28-Day study in young rats (including the dose- finding study)}

In the 14-day dose-finding study at doses of 20, 60,200 and $600 \mathrm{mg} / \mathrm{kg}$, all animals died within 6 days after the first treatment in the highest group. They showed various toxic signs such as decrease in spontaneous movement, oligopnea and adoption of a prone/ lateral position. Blood biochemical examination showed increase in total protein in males and in total cholesterol in females at $200 \mathrm{mg} / \mathrm{kg}$. Increase in absolute and relative liver weights was observed in both sexes of the 60 and $200 \mathrm{mg} / \mathrm{kg}$ groups and relative liver weights in males of $10 \mathrm{mg} / \mathrm{kg}$. In addition, increase was found in relative kidney weights in males and in absolute and relative kidney and heart weights in females at $200 \mathrm{mg} / \mathrm{kg}$. There were no other doserelated changes evident. Based on the results, $250 \mathrm{mg} /$ $\mathrm{kg}$, at which it was predicted that clear toxic signs would appear, was selected as the top dose for the main study, and by one-fifth division 50 and $10 \mathrm{mg} / \mathrm{kg}$ were derived.

In the main study, salivation was observed from dosing Day 12 in 5 to 10 of each sex given $250 \mathrm{mg} / \mathrm{kg}$. In males at this dose, body weights were significantly lowered by approx. $10 \%$ from dosing Day 18 , in spite of no dose-related change in food consumption. On

Table 1. Histological findings for the liver after 18-day repeat dosing of 1,3-dibromopropane in newborn rats (main study).

\begin{tabular}{|c|c|c|c|c|c|}
\hline & \multirow[b]{2}{*}{ Grade } & \multicolumn{4}{|c|}{ Dose $(\mathrm{mg} / \mathrm{kg})$} \\
\hline & & 0 & 10 & 50 & 150 \\
\hline \multicolumn{6}{|l|}{ Males } \\
\hline \multirow{2}{*}{\multicolumn{6}{|c|}{ Liver }} \\
\hline & & & & & \\
\hline - Single cell necrosis & \pm & 0 & 0 & 0 & 3 \\
\hline \multirow[t]{2}{*}{ - Centrilobular hypertrophy of hepatocytes } & \pm & 0 & 0 & 0 & 3 \\
\hline & + & $\stackrel{0}{\llcorner}$ & 0 & 0 & 3 \\
\hline Females & & \multicolumn{4}{|c|}{$*$} \\
\hline $\begin{array}{l}\text { No. of animals examined } \\
\text { Liver }\end{array}$ & & 6 & 6 & 6 & 6 \\
\hline - Single cell necrosis & \pm & 0 & 0 & 0 & 1 \\
\hline - Centrilobular hypertrophy of hepatocytes & \pm & 0 & 0 & 0 & 2 \\
\hline & + & 0 & 0 & 0 & 4 \\
\hline
\end{tabular}

士: Slight, +: Mild, *: Significantly different from the control group $(\mathrm{p}<0.01)$.

Table 2. Summary of the results of the repeated dose studies of 1,3-dibromopropane in newborn rats.

\begin{tabular}{|c|c|c|c|c|c|c|c|}
\hline \multirow[b]{2}{*}{ Dose $(\mathrm{mg} / \mathrm{kg} /$ day $)$} & \multicolumn{4}{|c|}{ Dose-finding Study (5 rats/sex/dose) } & \multicolumn{3}{|c|}{ Main Study (6 rats/sex/dose) } \\
\hline & 10 & 30 & 100 & 200 & 10 & 50 & 150 \\
\hline \multicolumn{8}{|l|}{ Toxic Effects } \\
\hline - Death (No. of dead animals) & 0 & 0 & 0 & $2 \mathrm{M}, 2 \mathrm{~F}$ & 0 & 0 & 0 \\
\hline - Body weight & - & - & - & $15-25 \% \downarrow$ & - & - & $10 \% \downarrow$ \\
\hline - Blood biochemical parameters & - & - & - & F: Cho $(\uparrow)$ & - & - & $\begin{array}{c}\text { M: GTP } \uparrow \\
\text { F: TB } \uparrow\end{array}$ \\
\hline - Relative liver weight & - & - & $\uparrow$ & $\uparrow$ & $\mathrm{F}: \uparrow$ & $\uparrow$ & $\uparrow$ \\
\hline - Histopathological changes & n.d. & n.d. & n.d. & n.d. & 0 & 0 & $3 \mathrm{M}, 2 \mathrm{~F}$ \\
\hline (No of animals with the findings*) & n.d. & n.d. & n.d. & n.d. & 0 & 0 & $3 \mathrm{M}, 4 \mathrm{~F}$ \\
\hline
\end{tabular}

\pm : Slight change, +: Mild change, M: Males, F: Females, $\uparrow:$ Increase, $\downarrow$ : Decrease, $(\uparrow)$ : Slight increase, $-:$ No change,

Cho: Total cholesterol, GTP: $\gamma$-GTP, TP: Total protein, n.d.: No available data, *Centrilobular hypertrophy of hepatocytes. 
Susceptibility of newborn rats to 1,3-dibromopropane and 1,1,2,2-tetrabromoethane.

hematological examination at the scheduled sacrifice, slight anemic changes with decrease in $\mathrm{Hb}$ and $\mathrm{Ht}$, and an increased reticulocyte ratio were observed in females receiving $250 \mathrm{mg} / \mathrm{kg}$. At $250 \mathrm{mg} / \mathrm{kg}$, many blood biochemical parameters, including total protein, albumin, total cholesterol, triglycerides, phospholipids and total bilirubin, were also increased with an upward trend of GOT and GPT. With $50 \mathrm{mg} / \mathrm{kg}$, slight increase in total protein was only observed in males. Significant increases were found in absolute and relative liver weights of both sexes at $250 \mathrm{mg} / \mathrm{kg}$ and in relative liver weights of females at $50 \mathrm{mg} / \mathrm{kg}$. There was also increase in relative heart weights and relative kidney weights in both sexes of the $250 \mathrm{mg} / \mathrm{kg}$ group. On histopathological examination, slight to mild centrilobular hypertrophy of hepatocytes was observed at $50 \mathrm{mg} /$ $\mathrm{kg}$ and more (Table 3). Perilobular vacuolation of hepatocytes tended to decrease with the dose. Most of the above changes became less prevalent or disappeared during the recovery period. However, body weights remain lower throughout this period in males and the relative liver and heart weights continued to be

Table 3. Histological findings in the repeated dose study of 1,3-dibromopropane in young rats (main study).

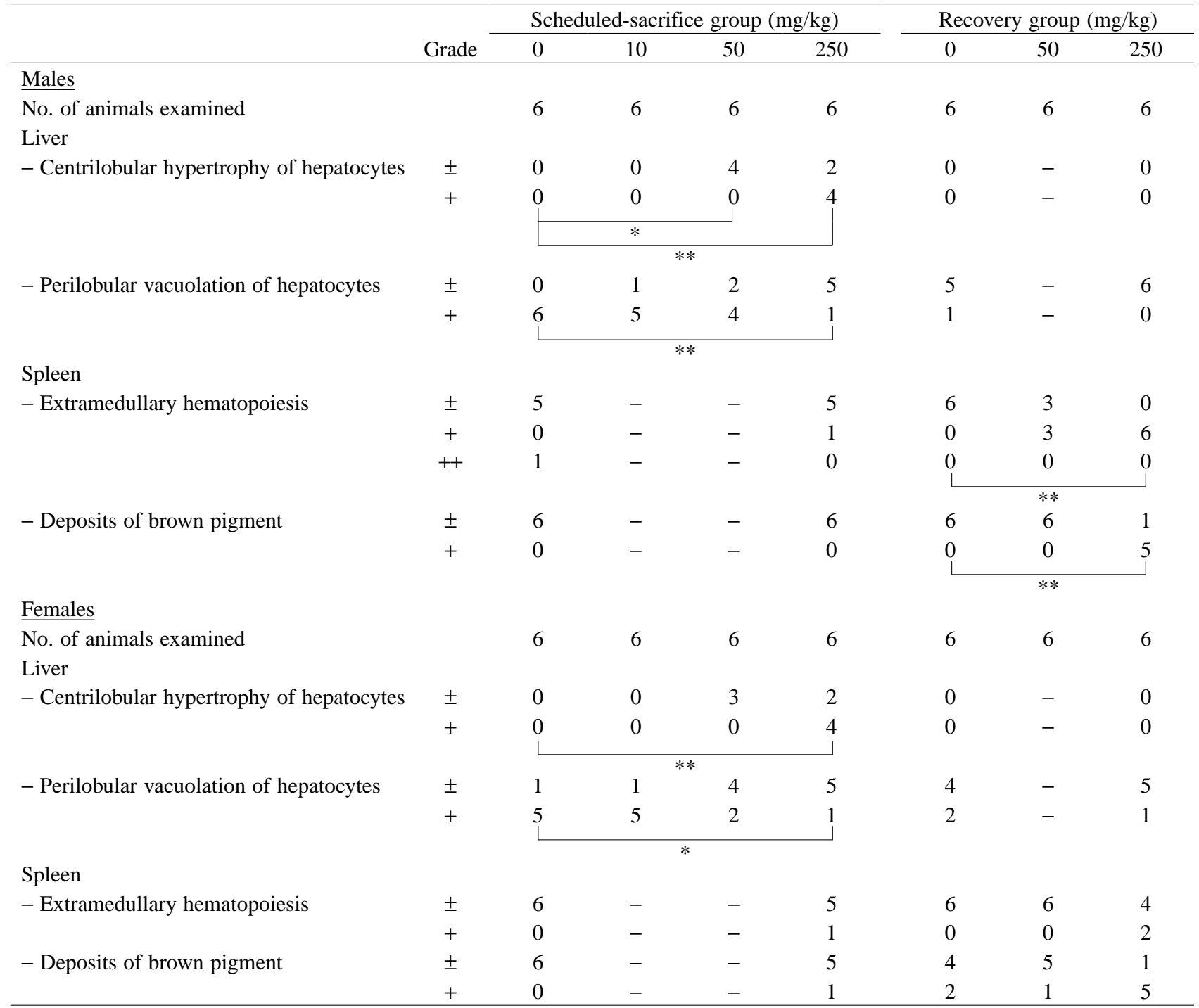

土: Slight, +: Mild, ++: Moderate, *: Significantly different from the control group $(\mathrm{p}<0.05)$,

**: Significantly different from the control group $(\mathrm{p}<0.01)$. 


\section{HIRATA-KOIZUMI et al.}

high in females at $250 \mathrm{mg} / \mathrm{kg}$. At the same time, decreases in $\mathrm{RBC}, \mathrm{Hb}, \mathrm{Ht}$ and increase in the reticulocyte ratio appeared in males given $250 \mathrm{mg} / \mathrm{kg}$ with an increased incidence of extramedullary hematopoiesis and deposits of brown pigment in the spleen (Table 3).

Summary of the results of the dose-finding and main study of DBP in young rats are shown in Table 4. The NOAEL was concluded to be $10 \mathrm{mg} / \mathrm{kg} /$ day from the main study, as the $20 \mathrm{mg} / \mathrm{kg}$ in dose-finding study was not appropriate because of the lack of histopathological examination. The unequivocally toxic level was concluded to be $250 \mathrm{mg} / \mathrm{kg} / \mathrm{day}$, at which increase of liver weight, mild centrilobular hypertrophy of hepatocytes, increase of many biochemical parameters with an upward trend of GOT and GPT, slight anemic effects and lowering body weight were observed in the main study.

\section{1,1,2,2-Tetrabromoethane (TBE)}

\section{18-Day study in newborn rats (including the dose- finding study)}

In the dose-finding study, when newborn rats were given TBE at 12,50 and $200 \mathrm{mg} / \mathrm{kg}$, hypoactivity and bradypnea were observed during the dosing period in all animals of the high dose group, the body weights being lowered by $10-20 \%$ in both sexes at dosing Days 8 to 17 . On blood biochemical examination for this group, slight increase in total bilirubin was found in both sexes. In addition, absolute and relative liver weights were increased in females receiving the $50 \mathrm{mg} /$ $\mathrm{kg}$ and both sexes of the $200 \mathrm{mg} / \mathrm{kg}$ group, and relative liver weights in females of the $12 \mathrm{mg} / \mathrm{kg}$ and males of the $50 \mathrm{mg} / \mathrm{kg}$ groups. There were also increases in relative kidney weights of females and decreases in abso- lute spleen weights of both sexes and relative spleen weights of females at $200 \mathrm{mg} / \mathrm{kg}$. No significant changes were observed on hematological and gross examination. Based on these results, it was predicted that some hepatotoxicity would be observed at $50 \mathrm{mg} /$ $\mathrm{kg}$, which was selected as the top dose in the main study, and 3 and $12 \mathrm{mg} / \mathrm{kg}$ were derived by approx. one-fourth divisions.

In the main study, no significant changes were noted in general behavior and body weight (Fig.2). There were also no definitive changes in the parameters for external and sexual development and reflex ontogeny at any dose. At scheduled sacrifice, blood biochemical examination in the $50 \mathrm{mg} / \mathrm{kg}$ group showed only a slight increase in total protein in males. There were also increases in absolute and relative liver weights in both sexes, relative kidney weights in males and relative heart weights in females of the $50 \mathrm{mg} / \mathrm{kg}$ group. After the recovery-maintenance period, no significant changes were observed in blood biochemical findings and in kidney and heart weights, but the relative liver weights still remained high in males at $50 \mathrm{mg} /$ $\mathrm{kg}$. There were no dose-related changes in food consumption, urinalysis, hematology and histopathology throughout the study, including the recovery-maintenance period.

As shown in summary of the results in Table 5, in the $50 \mathrm{mg} / \mathrm{kg}$ group, relative liver weights were increased in both dose-finding and main studies, and total protein was slightly increased only in males of the main study. These changes without histopathological alteration were not considered adverse effects. Therefore, the NOAEL was concluded to be $50 \mathrm{mg} / \mathrm{kg} / \mathrm{day}$. Unfortunately, no histopathological changes in the

Table 4. Summary of the results of the repeated dose studies of 1,3-dibromopropane in young rats.

\begin{tabular}{|c|c|c|c|c|c|c|c|}
\hline \multirow[b]{2}{*}{ Dose (mg/kg/day) } & \multicolumn{4}{|c|}{ Dose-finding Study (5 rats/sex/dose) } & \multicolumn{3}{|c|}{ Main Study(6 rats/sex/dose $)$} \\
\hline & 20 & 60 & 200 & 600 & 10 & 50 & 250 \\
\hline Toxic Effects & & & & & & & \\
\hline -Death (No. of dead animals) & 0 & 0 & 0 & $5 \mathrm{M}, 5 \mathrm{~F}$ & 0 & 0 & 0 \\
\hline -Body weight & - & - & - & n.d. & - & - & M: $10 \% \downarrow$ \\
\hline -Blood biochemical parameters & - & - & $\begin{array}{l}\mathrm{M}: \mathrm{TP} \uparrow \\
\mathrm{F}: \mathrm{Cho} \uparrow\end{array}$ & n.d. & - & $\mathrm{M}: \mathrm{TP}(\uparrow)$ & Many $\uparrow$ \\
\hline -Relative liver weight & & $\mathrm{M}: \uparrow$ & $\uparrow$ & n.d. & - & $\mathrm{F}: \uparrow$ & $\uparrow$ \\
\hline -Histopathological changes $\quad \pm$ & n.d. & n.d. & n.d. & n.d. & 0 & $4 \mathrm{M}, 3 \mathrm{~F}$ & $2 \mathrm{M}, 2 \mathrm{~F}$ \\
\hline (No of animals with the findings*) + & n.d. & n.d. & n.d. & n.d. & 0 & 0 & $4 \mathrm{M}, 4 \mathrm{~F}$ \\
\hline
\end{tabular}

\pm : Slight change, +: Mild change, M: Males, F: Females, $\uparrow:$ Increase, $\downarrow$ : Decrease, $(\uparrow)$ : Slight increase, $-:$ No change,

Cho: Total cholesterol, TP: Total protein, Many: Many parameters including Cho, TP, albumin, triglycerides, phospholipids and total bilirubin, n.d.: No available data, * Centrilobular hypertrophy of hepatocytes. 
Susceptibility of newborn rats to 1,3-dibromopropane and 1,1,2,2-tetrabromoethane.

liver were observed at the highest dose of $50 \mathrm{mg} / \mathrm{kg}$ in the main study, meaning that the dose setting was not appropriate. Therefore, an unequivocally toxic level could not be estimated. The dose of $200 \mathrm{mg} / \mathrm{kg}$ in the dose-finding study was clearly toxic because of effects on the central nervous system (hypoactivity and bradypnea) and lowering of body weight (10-20\% reduction), although no histopathological examination was conducted.

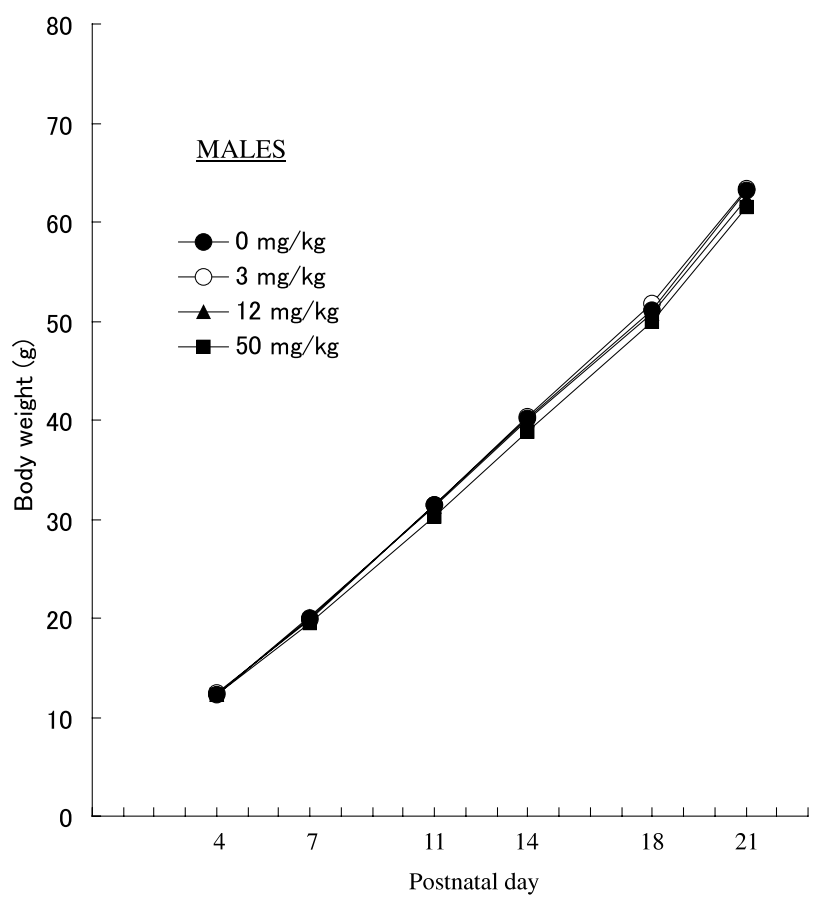

\section{28-Day study in young rats (including the dose- finding study)}

In the dose-finding study with 14-day exposure at $0,10,20,50,100$ or $200 \mathrm{mg} / \mathrm{kg}$, there were no significant changes in body weight, food consumption and urinalysis at any dose. Hematological examination showed increase in reticulocytes of both sexes at 200 $\mathrm{mg} / \mathrm{kg}$, and decrease in $\mathrm{Hb}$ in both sexes at $200 \mathrm{mg} / \mathrm{kg}$ and in males at $100 \mathrm{mg} / \mathrm{kg}$, as well as $\mathrm{Ht}$ in males at 100 and $200 \mathrm{mg} / \mathrm{kg}$ and RBC in females at $200 \mathrm{mg} / \mathrm{kg}$. On blood biochemical examination, increases in total

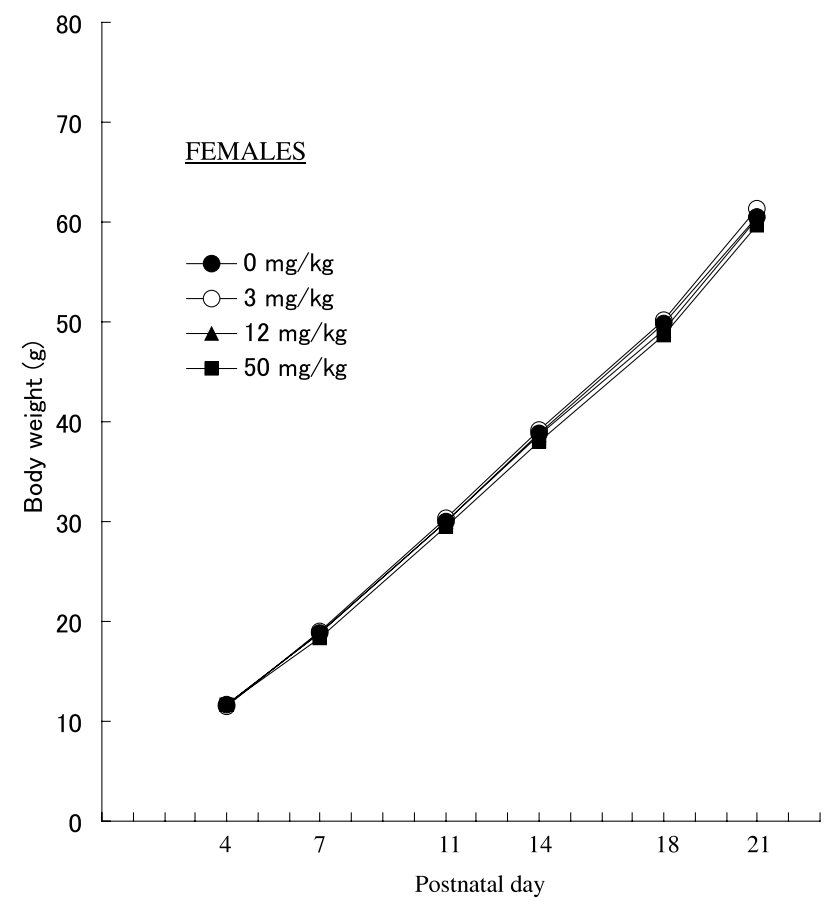

Fig. 2. Body weight curves in the 18-day study of 1,1,2,2-tetrabromoethane in newborn rats. Not significantly different from the controls.

Table 5. Summary of the results of the repeated dose studies of 1,1,2,2-tetrabromoethane in newborn rats.

\begin{tabular}{|c|c|c|c|c|c|c|}
\hline \multirow[b]{2}{*}{ Dose (mg/kg/day) } & \multicolumn{3}{|c|}{ Dose-finding Study (4 rats/sex/dose) } & \multicolumn{3}{|c|}{ Main Study (6 rats/sex/dose) } \\
\hline & 12 & 50 & 200 & 3 & 12 & 50 \\
\hline \multicolumn{7}{|l|}{ Toxic Effects } \\
\hline -Death (No. of dead animals) & 0 & 0 & $0 *$ & 0 & 0 & 0 \\
\hline -Body weight & - & - & $10-20 \% \downarrow$ & - & - & - \\
\hline -Blood biochemical parameters & - & - & $\mathrm{TB}(\uparrow)$ & - & - & M: TP $(\uparrow)$ \\
\hline -Relative liver weight & $\mathrm{F}: \uparrow$ & $\uparrow$ & $\uparrow$ & - & - & $\uparrow$ \\
\hline $\begin{array}{l}\text {-Histopathological changes } \\
\text { (No of animals with the findings) }\end{array}$ & n.d. & n.d. & n.d. & 0 & 0 & 0 \\
\hline
\end{tabular}

M: Males, F: Females, $\uparrow:$ Increase, $\downarrow$ : Decrease, $(\uparrow)$ : Slight increase, - : No change, TB: Total bilirubin, TP: Total protein, n.d.: No available data, *Although there were no deaths in this group, hypoactivity and bradypnea were observed in all animals. 


\section{HIRATA-KOIZUMI et al.}

cholesterol in both sexes, and total protein and triglycerides in females were noted at $200 \mathrm{mg} / \mathrm{kg}$. In addition, increase in total cholesterol was found in females given $100 \mathrm{mg} / \mathrm{kg}$. There were also increases in absolute liver weight in males at 100 and $200 \mathrm{mg} / \mathrm{kg}$ and in females at $200 \mathrm{mg} / \mathrm{kg}$, relative liver weight in both sexes at 50 $\mathrm{mg} / \mathrm{kg}$ and more, and kidney weights in females at 100 $\mathrm{mg} / \mathrm{kg}$ and in both sexes at the highest dose. Because of the clear toxic effects, $200 \mathrm{mg} / \mathrm{kg}$ was selected as the top dose for the main study, and 60,20 and $6 \mathrm{mg} / \mathrm{kg}$ were derived by one third division.

In the main study, there were no significant changes in body weight and food consumption. At scheduled sacrifice, hematological examination showed decrease in platelet counts in females of 200 $\mathrm{mg} / \mathrm{kg}$ group. On blood biochemical examination, changes suggestive of effects on the liver, including increase in total protein, albumin, A/G, total cholesterol, were found in both sexes at the highest dose. There were also increases in total protein and albumin in females of the 20 and $60 \mathrm{mg} / \mathrm{kg}$ groups and increases in $\mathrm{A} / \mathrm{G}$ in females of the $60 \mathrm{mg} / \mathrm{kg}$ groups. For organ weights, there were increases in absolute and relative liver weights of both sexes given 60 and $200 \mathrm{mg} / \mathrm{kg}$ and slight increase in relative liver weights in males given $20 \mathrm{mg} / \mathrm{kg}$. In addition, relative kidney weights were higher in both sexes and absolute kidney weights in females of the $200 \mathrm{mg} / \mathrm{kg}$ group. On histopathological examination (Table 6), slight to mild centrilobular hypertrophy of hepatocytes was observed in both sexes given $20 \mathrm{mg} / \mathrm{kg}$ and more. In the thyroid, mild hypertrophy of follicular cells was found at $60 \mathrm{mg} / \mathrm{kg}$ and $200 \mathrm{mg} / \mathrm{kg}$, and follicles were apt to be miniaturized and colloid to be decreased. At the end of the recovery period, changes observed in the scheduled-sacrifice group remained significant but with a tendency for recovery (total protein, total cholesterol, liver and thyroid weights, centrilobular hypertrophy of hepatocytes (Table 6)).

The results of the dose-finding and main study in young rats are summarized in Table 7. As slight hypertrophy of hepatocytes was observed at $20 \mathrm{mg} / \mathrm{kg}$ in the main study, the NOAEL was concluded to be $6 \mathrm{mg} / \mathrm{kg} /$ day. The unequivocally toxic level was considered to

Table 6. Histological findings in the repeated dose study of 1,1,2,2-tetrabromoethane in young rats (main study).

\begin{tabular}{|c|c|c|c|c|c|c|c|c|}
\hline & & & & $\mathrm{sacr}$ & oup & & $\operatorname{Rec}$ & roup \\
\hline & Grade & 0 & 6 & 20 & 60 & 200 & 0 & 200 \\
\hline Males & & & & & & & & \\
\hline No. of animals examined & & 5 & 5 & 5 & 5 & 5 & 5 & 5 \\
\hline Liver & & & & & & & & \\
\hline - Centrilobular hepatocyte hypertrophy & \pm & 0 & 0 & 3 & 4 & 0 & 0 & 3 \\
\hline & + & 0 & 0 & 0 & 0 & 5 & 0 & 0 \\
\hline & & & & & & & & \\
\hline & & & & $* *$ & & & & \\
\hline - Focal necrosis & \pm & 2 & 1 & 3 & 1 & 5 & 1 & 0 \\
\hline Thyroid & & & & & & & & \\
\hline - Hypertrophy of follicular cells & \pm & 0 & 0 & 0 & 1 & 4 & 0 & 0 \\
\hline Females & & & & & & & & \\
\hline No. of animals examined & & 5 & 5 & 5 & 5 & 5 & 5 & 5 \\
\hline Liver & & & & & & & & \\
\hline - Centrilobular hepatocyte hypertrophy & \pm & 0 & 0 & 3 & 5 & 1 & 0 & 2 \\
\hline & + & 0 & 0 & 0 & 0 & 4 & 0 & 0 \\
\hline & & & & & & & & \\
\hline & & & & $* *$ & & & & \\
\hline - Focal necrosis & \pm & 0 & 0 & 0 & 0 & 1 & 0 & 0 \\
\hline Thyroid & & & & & & & & \\
\hline - Hypertrophy of follicular cells & \pm & 0 & 0 & 0 & 2 & 5 & 0 & 0 \\
\hline
\end{tabular}

土: Slight, +: Mild, *: Significantly different from the control group $(\mathrm{p}<0.05), * *$ : Significantly different from the control group (p<0.01). 
Susceptibility of newborn rats to 1,3-dibromopropane and 1,1,2,2-tetrabromoethane.

be more than $200 \mathrm{mg} / \mathrm{kg}$ because of the lack of effects on body weights and parameters indicative of hepatotoxicity, such as GOT and GPT. Hypertrophy in the liver and thyroid, and increases in some biochemical parameters at this dose were not considered to be sufficient for a conclusion of toxicity.

\section{DISCUSSION}

As with human neonates, the metabolic ability of the newborn rat is known to be extremely immature, with a low cytochrome P450 content (Rich and Boobis, 1997 ) and a low capacity for glucuronidation (Gow et al., 2001). Therefore, it could be predicted that chemicals directly exerting adverse effects might show stronger toxicity in the newborn than in young/adult rats. As expected, our previous comparative studies demonstrated that the susceptibility to four chemicals (4nitrophenol, 2,4-dinitorophenol, 3-aminophenol, 3methylphenol), which may exert toxicity without metabolic activation, was 2 to 4 times greater in the newborn than in young rats (Koizumi et al., 2001, 2002, 2003).

In the present study, DBP and TBE, which differ from the earlier chemicals in requiring biotransformation differently from previous chemicals, were therefore examined. Although hitherto there has been no information on the repeated dose toxicity of DBP, hepatotoxicity with slight centrilobular fatty degeneration or cytoplasmic vacuolization has been already reported for TBE (Hollingsworth et al., 1963; NTP, 1996). The present study showed no effects of either chemical on early development in the newborn, but they caused hepatotoxicity, regardless of sex, in both newborn and young animals. The ratios for NOAELs and unequivocally toxic levels (young/newborn rats) for both chemicals are given in Table 8, the NOAELs for DBP and TBE being considerably higher in newborn than in young rats, so that the latter are clearly more susceptible. Unequivocally toxic levels could not be simply estimated for both chemicals because the hepatic influence observed was only hypertrophy of hepatocytes, usually without increase of GOT and GPT. Therefore, values were estimated on the basis of simultaneous changes of organ weights, histopathology, biochemical parameters and body weights. Based on our specified criteria, the unequivocally toxic level for DBP was in contrast lower in newborn than in young rats. Unfortunately an unequivocally toxic level of TBE could not be estimated for newborn or young rats. However, the dose of $200 \mathrm{mg} / \mathrm{kg}$ in the newborn dose-finding study was considered to be sufficiently toxic because of the $10-20 \%$ lowering of body weights observed, although no histopathology was conducted. The same dose in the young rat main study caused mild hypertrophy of hepatocytes but no change of body weights, was not considered a sufficient toxic level. These results suggest that the unequivocally toxic level of TBE in the newborn might be lower than that in young rats. The reasons for difference in susceptibility presumably lie with metabolic pathways and specific characteristics of newborn animals.

Three studies have demonstrated that DBP is conjugated with hepatic glutathione before or after oxidative biotransformation, leading to urinary excretion of cysteine or mercapturic acid derivatives and exhalation of $\mathrm{CO}_{2}$ (James et al., 1981, Jones and Wells, 1981, Onkenhout et al., 1986). Activity of the conjugation

Table 7. Summary of the results of the repeated dose studies of 1,1,2,2-tetrabromoethane in young rats.

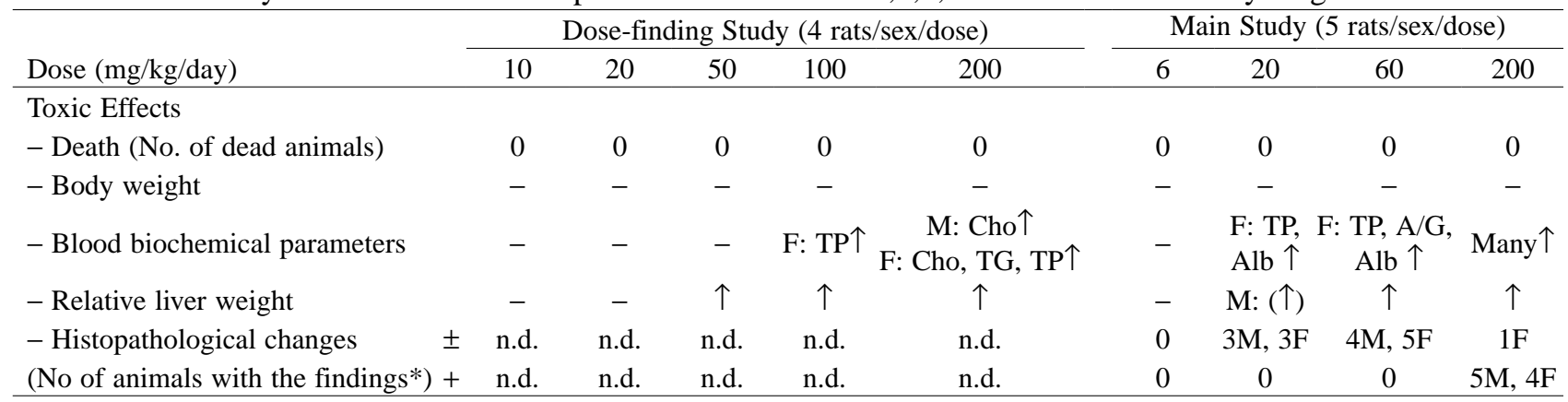

士: Slight, +: Mild, M: Males, F: Females, $\uparrow:$ Increase, $\downarrow$ : Decrease, $(\uparrow)$ : Slight increase, -: No change, Alb: Albumin, Cho: Total cholesterol, TG: Triglycerides, TP: Total protein, Many: Many parameters including Alb, A/G, Cho and TP, n.d.: No available data, * Centrilobular hypertrophy of hepatocytes. 


\section{HIRATA-KOIZUMI et al.}

pathway is supported by a rapid drop in hepatic glutathione level after DBP administration (James et al., 1981). Metabolism via conjugation with glutathione has in fact been indicated in common for dihaloalkanes or dihaloalkenes, such as 1,2-dibromopropane (Zoetemelk et al., 1986), 1,2-dichloropropane (Trevisan et al., 1989), 1,1-dichloroethylene (Jones and Hathway, 1978) and 1,3-dichloropropene (Climie et al., 1979). In the case of 1,2-halogenated ethanes, it is considered that the oxidative metabolites might irreversibly bind to protein and that conjugate derivatives, episulphonium ions, might be responsible for the DNA adduct formation (Shih and Hill, 1981; Ozawa and Guengerich, 1983).

With TBE, Kennedy et al. (1993) identified various excretory metabolites after a single oral administration to rats, such as 1,2-dibromoethylene and tribromoethylene in exhaled air and dibromoacetic acid, glyoxylic acid, and oxalic acid in urine. They suggested that a number of metabolic intermediates produced by oxidative biotransformation may be involved in the mutagenicity, hepatotoxicity and nephrotoxicity of the compound. At least, dibromoacetic acid has unequivocal cytotoxicity and mutagenicity (Kargalioglu et al., 2002).

Based on the available information, oxidative biotransformation mediated by cytochrome $\mathrm{P} 450$ might be a critical step for the initial hepatotoxic effects of both chemicals. The rate of production of active metabolites, including free radical intermediates, would be expected to be significantly less or negligible in newborn animals at least around $50 \mathrm{mg} / \mathrm{kg}$, at which clearly hepatic changes were observed in young rats for both chemicals, because of their lower content of cytochrome P450 (Rich and Boobis, 1997). This metabolic character for both chemicals as well as the lower blood flow to the liver during the newborn period (Gow et al., 2001) would make a major contribution to the much higher NOAEL in the newborn than in young rats. Similar results have already been demonstrated for aflatoxin B1 (Behroozikha et al., 1992), acetaminophen, bromobenzene and carbon tetrachloride (Gergus and Klaassen, 1998). On the other hand, unequivocally toxic levels for both chemicals appeared to be only 3 to 4 times higher than the NOAELs in newborn rats, in contrast to 25 to $>33$ times higher in their young counterparts (Table 8). One possible explanation for these differences might be a low capacity for protection against deleterious oxidative stress in the newborn when the toxic chemical burden crosses a threshold in the liver. It has been reported that the content of glutathione and glutathione- $S$-transferase activity in rat liver drops in the early days after birth (Tee $e t$ al., 1992).

In our series of comparative studies, the results of the repeated dose toxicity study using newborn rats have been compared with those of routine repeated dose toxicity studies. The routine repeated dose studies have value in identifying target sites for toxicity and providing dose-response information that may be useful for human safety assessment, irrespective of life stage, but the developing period, which could be most vulnerablev to chemical toxicity during life, is not directly evaluated by the studies (Dourson et al., 2002). To compensate for this period, reproductive/developmental toxicity studies that exposed the developing animals via placenta or maternal milk have been conducted. However, the direct exposure to chemicals dur-

Table 8. Comparison of NOAELs and unequivocally toxic levels in newborn and young rats.

\begin{tabular}{|c|c|c|}
\hline & Level (mg/kg/day) & Ratio (young/newborn) \\
\hline \multicolumn{3}{|l|}{ 1,3-Dibromopropane } \\
\hline$\overline{\text { NOAEL (newborn) }}$ & 50 & \multirow{2}{*}{0.2} \\
\hline NOAEL (young) & 10 & \\
\hline Unequivocally toxic level (newborn) & $150 \leadsto$ & \multirow{2}{*}{1.67} \\
\hline Unequivocally toxic level (young) & 2504 & \\
\hline \multicolumn{3}{|l|}{ 1,1,2,2,-Tetrabromoethane } \\
\hline NOAEL (newborn) & 50 & \multirow{2}{*}{0.12} \\
\hline NOAEL (young) & $\times 4 \%$ & \\
\hline Unequivocally toxic level (newborn) & $200 * 4$ & \multirow{2}{*}{$>1.0^{*}$} \\
\hline Unequivocally toxic level (young) & $>200 *$ & \\
\hline
\end{tabular}

*: Tentative levels or ratios, due to lack of histology alteration in the newborn and no change in body weight in young rats. 
Susceptibility of newborn rats to 1,3-dibromopropane and 1,1,2,2-tetrabromoethane.

ing the newborn period is not included in these studies, despite the significant possibility that the newborn are exposed to chemicals directly via mouthing toys and household materials, or having chemical-contaminated milk and baby food, and so on. In the routine repeated dose toxicity study, rats at approximately 5-6 weeks of age have generally been used, and this start period is largely a matter of practical convenience and feasibility. Rats much younger than this age, especially newborn rats, are so difficult to handle such as grouping, direct dosing and other testing or observation. Economic issues and lack of the human resource with this technical difficulty make it impossible to subject the newborn rat study to the routine one. Our series of comparative studies are the first systematic study to look into the direct effects of chemicals in newborn animals, and the comparative analysis on the susceptibility of the newborn rats to the toxicity of chemicals with that of young rats would give important information for considering the effects by chemical exposure during the newborn period in risk assessment.

In conclusion, the target organ of DBP and TBE was here found to be the liver in both newborn and young rats, but the doses at which the toxic signs began to appear were higher in newborn rats. In contrast, the doses at which clear toxicity was observed appeared to be lower in the newborn case. However, no special concern with regard to newborn risk is necessary in cases of chemicals which induce toxicity after biotransformation via hepatic cytochrome $\mathrm{P} 450$, because the tolerable daily intake (TDI) used for regulation is generally derived from NOAEL in toxicity studies in young/adult animals.

\section{ACKNOWLEDGMENT}

The authors gratefully acknowledge the financial support of the Office of Chemical Safety, Pharmaceutical and Medical Safety Bureau, Ministry of Health, Labor and Welfare, Japan.

\section{REFERENCES}

Alcorn, J. and McNamara, P.J. (2002): Ontogeny of hepatic and renal systemic clearance pathways in infants: Part I. Clin. Pharmacokinet., 41, 959998.

Bartlett, M.S. (1937): Properties of sufficiency and statistical tests. Proc. Royal Soc. London, Series A, 160, 268-282.

Behroozikha, M., Saidee, M. and Allameh, A. (1992):
Comparison of aflatoxin B1-DNA binding and glutathione conjugate formation by liver preparations from rats of different ages. Cancer Lett., 66, 69-76.

Chemical Products' Handbook (2004): Chemical Products of 14504 "14504 no Kagakushohin" published by The Chemical Daily Co., Ltd., Tokyo (in Japanese).

Climie, I.J., Hutson, D.H., Morrison, B.J. and Stoydin, G. (1979): Glutathione conjugation in the detoxication of (Z)-1,3-dichloropropene (a component of the nematocide D-D) in the rat. Xenobiotica, 9, 149-156.

Dourson, M., Charnley, G. and Scheuplein, R. (2002): Differential sensitivity of children and adults to chemical toxicity. II. Risk and regulation. Regul. Toxicol. Pharmacol., 35, 448-467.

Dunnett, C.W. (1964): New tables for multiple comparisons with a control. Biometrics, 20, 482491.

Fisher, R.A. (1922): On the interpretation of chisquare from contingency tables and the calculation of P. J. Royal Stat. Sci., 85, 87-94.

Fisher, R.A. (1973): Statistical Methods of Research Workers. 14th edition, p.6. Hapner Publishing Company, New York.

Fukuda, N., Ito, Y., Yamaguchi, M., Mitumori, K., Koizumi, M., Hasegawa, R., Kamata, E. and Ema, M. (2004): Unexpected nephrotoxicity induced by tetrabromobisphenol A in newborn rats. Toxicol. Lett., 150, 145-155.

Gergus, Z. and Klaassen, C.D. (1998): Hepatic disposition of xenobiotics during prenatal and postnatal development. In Fetal and Neonatal Physiology (Polin, R.A. and Fox, W.F., eds.), pp. 1472-1493. Saunders, Philadelphia.

Gow, P.J., Ghabrial, H., Smallwood, R.A., Morgan, D.J. and Ching, M.S. (2001): Neonatal hepatic drug elimination. Pharmacol. Toxicol., 88, 3-15.

Hollander, M. and Wolfe, D.A. (1973): Nonparametric Statistical Methods. John Wiley and Sons, New York.

Hollingsworth, R.L., Rowe, V.K. and Oyen, F. (1963): Toxicity of acetylene tetrabromide determined on experimental animals. Arch. Ind. Hyg. Assoc. J., 24, 28-35.

James, S.P., Pue, M.A. and Richards, D.H. (1981): Metabolism of 1,3-dibromopropane. Toxicol. Lett., 8, 7-15.

Jones, A.R. and Wells, G. (1981): The metabolism of 1,3-dibromopropane by the rat. Xenobiotica, 11, 
541-546.

Jones, B.D. and Hathway, D.E. (1978): The biological fate of vinylidene chloride in rats. Chem. Biol. Interact., 20, 27-41.

Kargalioglu, Y., McMillan, B.J., Minear, R.A. and Plewa, M.J. (2002): Analysis of the cytotoxicity and mutagenicity of drinking water disinfection by-products in Salmonella typhimurium. Teratog. Carcinog. Mutagen., 22, 113-128

Kennedy, C.H., Cohen, K.B., Bechtold, W.E., Chang, I.Y., Eidson, A.F., Dahl, A.R. and Henderson, R.F. (1993): Effect of dose on the metabolism of 1,1,2,2-tetrabromoethane in F344/N rats after gavage administration. Toxicol. Appl. Pharmacol., 119, 23-33.

Koizumi, M., Yamamoto, Y., Ito, Y., Takano, M., Enami, T., Kamata, E. and Hasegawa, R. (2001): Comparative study of toxicity of 4-nitrophenol and 2,4-dinitrophenol in newborn and young rats. J. Toxicol. Sci., 26, 299-311.

Koizumi, M., Nishimura, N., Enami, T., Sunaga, M., Horikawa, H., Kamata, E. and Hasegawa, R. (2002): Comparative toxicity study of 3-aminophenol in newborn and young rats. J. Toxicol. Sci., 27, 411-421.

Koizumi, M., Noda, A., Ito, Y., Furukawa, M., Fujii, S., Kamata, E., Ema, M. and Hasegawa, R. (2003): Higher susceptibility of newborn than young rats to 3-methylphenol. J. Toxicol. Sci., 28, 59-70.

Mann, H.B. and Whiteny, D.R. (1947): On a test of whether one of two random variables is stochastically larger than the other. Ann. Math. Stat., 18, 50-60.

MHLW (2003a): 1,3-Dibromopropane (109-64-8). In Toxicity Testing Reports of Environmental Chemicals (Ministry of Health, Labor and Welfare ed.), Vol. 10, pp. 162-173, Chemicals Investigation Promoting Council, Tokyo.

MHLW (2003b): Tetrabromoethane (79-27-6). In Toxicity Testing Reports of Environmental Chemicals (Ministry of Health, Labor and Welfare ed.), Vol. 10, pp. 47-57, Chemicals Investigation Promoting Council, Tokyo.

NTP (1996): Renal toxicity studies of selected halogenated ethanes administered by gavage to $\mathrm{F} 344 / \mathrm{N}$ rats. NTP Technical Report Series, No. 45. NIH Publication No. 96-3935. U.S. Department of Human Services, Public Health Service, National Institutes of Health, North Carolina.

Onkenhout, W., Van Bergen, E.J., Van der Wart, J.H.,
Vos, G.P., Buijs, W. and Vermeulen, N.P. (1986): Identification and quantitative determination of four different mercapturic acids formed from 1,3-dibromopropane and its 1,1,3,3-tetradeutero analogue by the rat. Xenobiotica, 16, 21-33.

Ozawa, N. and Guengerich, F.P. (1983): Evidence for formation of an $S$-[2-(N7-guanyl)ethyl]glutathione adduct in glutathione-mediated binding of the carcinogen 1,2-dibromoethane to DNA. Proc. Natl. Acad. Sci. U.S.A., 80, 52665270 .

Rich, K.J. and Boobis, A.R. (1997): Expression and inducibility of P450 enzymes during liver ontogeny. Microsc. Res. Tech., 39, 424-435.

Sax, N.I. (1979): Dangerous properties of industrial materials, 5th ed. Van Nostrand Reinhold, New York.

Scheuplein, R., Charnley, G. and Dourson, M. (2002): Differential sensitivity of children and adults to chemical toxicity. I. Biological basis. Regul. Toxicol. Pharmacol., 35, 429-447.

Shih, T.W. and Hill, D.L. (1981): Metabolic activation of 1,2-dibromoethane by glutathione transferase and by microsomal mixed function oxidase: Further evidence for formation of two reactive metabolites. Res. Commun. Chem. Pathol. Pharmacol., 33, 449-461.

Snedecor, G.W. and Cochran, W.G. (1967): In Statistical Methods. 6th ed. The Iowa State University Press Ames, Iowa.

Steel, R.D. (1959): A multiple comparison rank sum test: Treatment versus control. Biometrics, 15, 560-572.

Steel, R.G.D. and Torrie, J.H. (1980): Principles and Procedures of Statistics, 2nd ed. McGraw-Hill Book Company, New York.

Tee, L.B., Gilmore, K.S., Meyer, D.J., Ketterer, B., Vandenberghe, Y. and Yeoh, G.C. (1992): Expression of glutathione $S$-transferase during rat liver development. Biochem. J., 282, 209218.

Trevisan, A., Rizzi, E., Scapinello, A., Gioffre, F. and Chiesura, P. (1989): Liver toxicity due to 1,2dichloropropane in the rat. Arch. Toxicol., 63, 445-449.

Zoetemelk, C.E., Oei, I.H., van Meeteren Walchli, B., Onkenhout, W., van der Gen, A. and Breimer, D.D. (1986): Biotransformation of 1,2-dibromopropane in rats into four mercapturic acid derivatives. Drug. Metab. Dispos., 14, 601-607. 